\title{
HUBUNGAN PENERAPAN KESELAMATAN PASIEN TERHADAP AKREDITASI RUMAH SAKIT
}

\author{
SRI HARVITA SARI MARPAUNG / 181101125
}

Sriharvitaaasm11@gmail.com

\begin{abstract}
ABSTRAK
Latar belakang : Status akreditasi merupakan pengakuan bahwa rumah sakit sudah memenuhi standar ter-masuk didalamnya standar MPO pada rumah sakit dengan status akreditasi. Masih tingginya insiden keselamatan pasien pada beberapa laporan di Indonesia mengindikasikan lemahnya hubungan status akreditasi dan keselamatan pasien. Tujuan : untuk memberikan informasi mengenai hubungan penerapan penerapan keselamatan pasien dengan akreditasi rumah sakit. Metode : Rancangan penugasan kajian ini menggunakan buku teks, buku referensi, jurnal, e-journal (10 tahun terakhir) dengan menganalis, eksplorasi dan kajian bebas. Hasil : Perawat berpendapat bahwa akreditasi mendorong perawat untuk lebih memperhatikan upaya keselamatan pasien di rumah sakit, diantaranya penerapan standar opeasional prosedur yang lebih baik dalam upaya pencegahan infeksi, mobilisasi pasien, dan asuhan keperawatan. Selain itu akreditasi juga mendorong perawat melakukan pendokumentasian secara lengkap, mendorong perawat melakukan pendidikan kesehatan kepada pasien dan keluarga secara intensif serta mendorong dokumentasi yang terintegrasi sehingga menimbulkan komunikasi antar tim kesehatan yang merawat pasien. Pembahasan : hubungan penerapan keselamatan pasien dengan akreditasi rumah sakit. Kesimpulan : Akreditasi sangat mempengaruhi keselamatan pasien karena dengan akreditasi yang baik maka akan dapat memberikan hasil terbaik untuk keselamatan pasien.
\end{abstract}

Kata kunci : akreditasi rumah sakit, keselamatan pasien, penerapan keselamatan pasien

\section{LATAR BELAKANG}

Patient safety merupakan prioritas, isu penting dan global dalam pelayanan kesehatan (Perry 2009). Ballard (2003) dalam Mustikawati (2011) menyatakan bahwa Patient safety merupakan komponen penting dan vital dalam asuhan keperawatan yang berkualitas. Hal ini menjadi penting karena Patient safety merupakan suatu langkah untuk memperbaiki mutu pelayanan dalam memberikan asuhan keperawatan

(Cahyono, 2008).

Keselamatan pasien merupakan isu global yang paling penting saat ini dimana sekarang banyak di laporlkan tuntutan pasien. World Health Organization (WHO) pada tahun 2004 mengumpulkan angkaangka penelitian rumah sakit di berbagai negara : Amerika, Inggris, Denmark, dan Australia, ditemukan Kejadian Tidak Diharapkan (KTD) dengan rentang 3,2 - 
16,6\%. Data-data tersebut menjadikan pemicu berbagai negara segera melakukan penelitian dan mengembangkan sistem keselamatan pasien (DepKep, 2008).

Mutu layanan kesehatan di rumah sakit perlu dilakukan pengukuran yaitu dengan pengukuran setiap dimensi mutu layanan kesehatan untuk mengetahui tingkat kepuasan pasien yang diberikan layanan.

Kurangnya kepuasan pasien terjadi karena dinamika tuntunan pasien yang demikian cepat berubah namun tidak di imbangi dengan kecepatan perubahan pola kerja dan tindakan perawat.

\section{TUJUAN}

Kajian ini bertujuan untuk mengetahui hubungan akreditasi rumah sakit dengan keselamatan pasien.

\section{METODE}

Jurnal ini penulis menggunakan Metode melakukan analisis data sekunder,yauitu kajian pustaka terhadap beberapa jurnal dan buku.

\section{HASIL}

Dari jurnal Jurnal Keperawatan Soedirman (The Soedirman Journal of Nursing), Volume 11, No.2, Juli 2016)
Terdapat hubungan antara pelaksanaan handover dengan Patient safety. Baik buruknya pelaksanaan handover dapat mempengaruhi patient safety. Elisabet (2008) menyatakan bahwa baik buruknya pelaksanaan handover ditunjang dengan adanya Standar Operasional Prosedur (SOP) dimana dalam SOP harus mencerminkan $4 \mathrm{~W}+1 \mathrm{H}$ (what, who, when, where, how) sehingga dapat menimbulkan kesinambungan dalam memberikan informasi secara cepat dan akurat tentang kondisi pasien dan proses keperawatan yang diberikan.

\section{PEMBAHASAN}

Menurut tenaga kesehatan, akreditasi dapat mendorong tenaga kesehatan untuk lebih memperhatikan upaya keselamatan pasien di rumah sakit, diantaranya penerapan standar opeasional prosedur yang lebih baik dalam upaya pencegahan infeksi, mobilisasi pasien, dan asuhan keperawatan. Selain itu akreditasi juga mendorong tenaga kesehatan melakukan pendokumentasian secara lengkap, mendorong perawat melakukan pendidikan kesehatan kepada 
Pasien dan keluarga secara intensif serta mendorong dokumentasi yang terintegrasi sehingga menimbulkan komunikasi antar tim kesehatan yang merawat pasien. Adanya komunikasi yang baik antar petugas medis ini sangat membantu dalam pelayanan kesehatan, karena beberapa penelitian menunjukkan bahwa komunikasi tenaga kesehatan dengan pasien belum cukup baik dan akibat dari hal ini adalah pelayanan kepada pasien menjadi tidak optimal.

Akibat persepsi bahwa akreditasi rumah sakit di Indonesia sangat bersih adalah adanya perbaikan fasilitas dan lingkungan rumah sakit. Hal ini tercermin dalam hasil wawancara tenaga kesehatan yang menyatakan bahwa dengan akreditasi fasilitas menjadi lebih lengkap dan aturan kawasan bebas merokok di rumah sakit benar-benar diterapkan.

Selain persepsi positif terhadap akreditasi, perawat juga menganggap akreditai sebagai ujian yang harus dihadapi untuk mendapatkan sertifikat pengakuan. Persepsi akreditasi sebagai ujian karena akreditasi rumah sakit di Indonesia masih bersifat menilai belum membina. Hal ini sangat berbeda dengan akreditasi yang dilakukan di Australia yang menggunakan akreditasi sebagai sarana pembinaan rumah sakit.

Tenaga kesehatan juga berharap agar semangat akreditasi ini tidak hanya selesai dengan selesainya penilaian. Persepsi positif ini sebaiknya dimanfaatkan sebaik-baiknya oleh pimpinan rumah sakit untuk memperbaiki pelayanan secara berkelanjutan. Semangat ini dapat dijadikan modal untuk meningkatkan pelayanan dengan penilian kualitas indikator klinis pelayanan sehingga pasien akan benar-benar merasakan perbedaan pelayanan yang diberikan rumah sakit.

Menurut penelitian yang dilakukan oleh Hughes (2008) dalam Kamil (2011) mengungkapkan bahwa faktor pelaksanaan handover tidak berjalan dengan baik disebabkan oleh faktor eksternal dan internal individu dan organisasi. Dewi (2012) mengatakan bahwa keselamatan pasien terlindungi melalui standar keselamatan pasien dan peningkatan penerapan keselamatan pasien oleh perawat dikarenakan adanya penerapan keselamatan diantaranya pengidentifikasian pasien, komunikasi efektif pada saat timbang terima, 
menghindari kesalahan pemberian obat, meniadakan kesalahan prosedur tindakan, mencegah infeksi nosokomial, serta pencegahan pasien jatuh. Sejalan dengan penelitian Johnson (2006) dalam Dewi (2012) bahwa adanya prosedur handover yang efektif dalam meningkatkan kesinambungan, kualitas serta keselamatan dalam memberikan pelayanan pada pasien.

Dalam melakukan handover terdapat hubungan dengan patient safety nah dalam hubungan itu terdapat efek yang membuat pasien merasa aman dan nyaman,nah dari itu jika patient safety berhasil di laksanakan dengan baik maka akreditasi rumahsakit akan meningkat dan baik. Sehingga pasien jika ingin berobat atau butuh pertolongan akan memilih rumah sakit tersebut, karena pasien akan memilih rumah sakit yang bagus pelayanannya dengan cara melihat akreditasi dari

Adisasmita, W. (2008). Kesiapan Rumah Sakit Dalam Menghadapi Globalisasi. Jakarta : Universitas Indonesia.

Anggraeni, D., Hakim, L., Widjiati, C. (2014). Evaluasi Pelaksanaan Sistem Identifikasi Pasien di rumah sakit tersebut. Jika rumah sakit tersebut berakreditasi bagus maka sudah tentu pelayanan di rumahsakit tersebut bagus.

\section{KESIMPULAN}

Bahwa jika pasien safety berjalan dengan baik dan sangat terjaga, maka pasien akan senang datang kerumah sakit tersebut. Dan oleh karena itu bahwa pasien safety berhubungan dengan akreditasi rumah sakit, jika pasien safety di suatu rumah sakit kurang baik maka akreditasi dalam rumah sakit tersebut pasti tidak akan naik.

Oleh karena itu sebagai perawatperawat yang di rumah sakit lebih meningkatkan wawasan tentang pasien safety agar pasien merasa senang dan akreditasi di rumah sakit meningkat dan menjadi rumah sakit favorit.

\section{REFERENSI}

Instalasi Rawat Inap Rumah Sakit. Jurnal Kedokteran Brawijaya. (Vol. 28, Suplemen No. 1).

Anjaryani, W. D. (2009). Kepuasan Pasien Rawat Inap Terhadap 
Pelayanan Perawat di RSUD Tugurejo Semarang.

Atisah. (2012). Hubungan antara pelayanan keperawatan profesional dengan penerapan patient safety di instalasi intensif Rumah Sakit Gunung Jati Cirebon. Skripsi. Stikes Mahardika Cirebon.

Bantu, A. (2014). Hubungan Pengetahuan Perawat Dengan Penerapan Patient Safety di RSUP Ratatotok Buyat Kabupaten Minahasa Tenggara. September 2014.

Cahyono, J.B. (2008). Membangun budaya keselamatan pasien dalam praktik kedokteran. Yogyakarta: Kanisius.

Dewi, M. (2012). Pengaruh pelatihahan timbang terima pasien terhadap penerapan keselamatan pasien oleh perawat pelaksana di RSUD Raden. Jurnal Health \& Sport, 5 (3).

Elisabet. (2008). Optimalisasi pelaksanaan handover berdasarkan standar national patient safety. Jurnal
Administrasi dan Kebijakan Kesehatan, 6:166-171.

Ilyas, Y. (2003). Kiat sukses manajemen tim kerja. Jakarta: PT. Gramedia Pustaka Utama.

Kamil, H. (2011). Handover dalam pelayanan keperawatan. Volume 4 No. 11 (102-116).

Mustikawati. (2011). Analisis determinan kejadian nyaris cedera dan kejadian tidak di harapkan di unit perawatan Rumah Sakit Pondok Indah Jakarta. Skripsi. Universitas Indonesia Jakarta.

Potter, P., \& Perry, A. (2005). Buku ajar fundamental keperawatan; konsep, proses \& praktik, Ed. 4. Jakarta: EGC

Soejadi. (1996). Pedoman penilaian kinerja rumah sakit umum. Jakarta : Katiga Bina. 